\title{
REMARRIAGE: A FAMILY DEVELOPMENTAL PROCESS
}

\author{
Mary F. Whiteside \\ University of Michigan Medical Center
}

\begin{abstract}
As family members move from first marriage, through divorce and the two household family, to early and then established remarriage, they face predictable periods of transition in which family structure is disrupted and reorganized. Clinical examples are used to illustrate the view that an understanding of the pain of transition and the effectiveness of reorganization must be placed in the context of (1) the challenges characteristic of the curnent phase in the divorce-remarriage cycle, (2) the life cycle issues of individual family members, and (3) the legacy of previous family structural organizations.
\end{abstract}

The remarried family system, like all forms of family organization, is not a static structure, but one which is continually evolving. As the literature on the separationdivorce-remarriage process increases, accumulating evidence points to fairly regularly occuring sequences that most people go through as they move from the family of first marriage through the family of established remarriage. Like all family developmental sequences, each stage in the process is a cycle of critical event which disrupts a stable equilibrium, a transition period, a re-establishment of equilibrium, followed by the next cycle of change. Each stage has its own challenges, tasks to be accomplished, and its own timing. The resolution of early stages has implications for patterns of coping and points of vulnerability in succeeding stages. Particularly interesting for the analysis of the remarried family, however, is that one has to take into account two developmental streams simultaneously. The remarried family goes through the developmental sequences related to the age and stage of the individual family members, but also is influenced by characteristics of the family system organization related to the family's stage in the remarriage process. An understanding of a remarried family structure developmentally must take into account the family's position on both developmental lines and its unique integration of these sets of developmental processes. The following is a beginning outline of implications of a developmental perspective in understanding the dynamics of remarried families. Examples will be drawn from the literature and from the author's clinical practice to illustrate the importance of adding to the current family situation both a view of critical points in a family's history and expectation for its future paths.

The remarriage developmental sequence refers to the following stages: first married family (usually with children); a period of parting which includes marital separation, divorce, and the establishment of two separate households; a courting period with plans for remarriage; early remarriage; and established remarriage. The three major family groupings-first marriage, one-parent (or joint custody), and remarried family-entail different forms of family organization in terms of family boundaries, the roles within the family, the legal ties, and the emotional relationships. Although there is continuity as a

Mary F. Whiteside, $\mathrm{PhD}$, is a Clinical Assistant Professor of Psychology in Psychiatry, Children's Psychiatric Hospital, University of Michigan Medical Center, Ann Arbor, MI 48109. 
family moves from one phase to the next, each transition requires significant disruption and change. In addition, the successful solution to the family needs of one phase may be very different, perhaps contradictory, to the necessary solution to similar family needs in the succeeding phase. When approaching a new stage family members have little chance for "anticipatory socialization" (Albrecht \& Gift, 1975) for the new roles they face. Without clear expectations for what is needed or expected in roles such as single parent, non-custodial parent, stepparent, and stepchild, family members cannot easily employ available coping skills, solutions to problems can be less easily reached, and the situation is more likely to be felt as a crisis.

Although the remarriage developmental sequence differs in major ways from the more naturally occurring developmental changes, the general principles characterizing family developmental transitions should remain applicable. Four dimensions of remarriage need to be considered as especially pertinent: the role of history, the disruptive character of transitions, regressive potential during transitions and re-equilibration.

\section{Role of history}

As discussed by Solomon (1973), each family developmental stage carries with it certain relationship tasks. Families must attend to the tasks of one stage before they can adequately cope with the tasks of the next. The patterns of relationship established in early phases of family life influence the patterns available in later stages, they affect what is experienced as disruptive as change is required, and determine the family's ability to successfully deal with the transitions. Relationship patterns which have developed to avoid dealing with unresolved issues may leave the family with a rigid structure, particularly vulnerable to disruption.

\section{Disruptive character of transitions}

Because periods of transition between stages are times at which the stability of system functioning has been disrupted and role complementarity has been lost (Spiegel, 1975), family members will experience heightened feelings of tension, anxiety, and confusion. It is a period which may be accompanied by the transitory appearance of symptoms in individual members as patterns of mutual expectation and interaction are disrupted and reformed. This will occur whether the transition is precipitated by a loss or by the happily expected and looked forward to remarriage.

\section{Regressive potential during transitions}

As discussed by Ravenscroft (1974) in terms of family reactions to adolescence, and more generally by Barnhill and Longo (1978), times of transition are times when not only current challenges are dealt with but also they are times when old, unresolved issues resurface. This offers the possibility of falling back into former dysfunctional solutions. Alternatively, it can be an opportunity for the family to develop new and more adaptive solutions.

\section{Re-equilibration}

Following a period of disruption there will be a gradual stabilization, and a lessening of the feeling of crisis as new patterns are established. These solutions can be dysfunctional, resisting the pressure for change, perhaps consolidating around the perceived vulnerability and need for protection of a family member. Or, the new patterns can accommodate to the need for change, allowing the evolution of newly differentiated roles and role relationships.

For the remarried family it is reasonable to expect to see characteristics of developmental stages and transitions occurring at each phase of the divorce-remarriage sequence as well as around "normal" developmental shifts for individual members. 
Assessment can be made not only of the expected challenges in forming the complex role constellation of the remarried family, but also of the tasks from earlier stages left unresolved. Each member's reaction to and ability to cope with a given family constellation will vary depending upon his or her age, developmental stage, and new family role.

\section{THE FIRST MARRIAGE}

There are several important areas to assess from the first marriage. Most simply are the questions of the length of time of the first marriage and the stage of family development at the point of separation. This information may give clues as to the unresolved issues involved in the decision to separate, and will give a perspective on the impact of the separation for each family member. For example, Hetherington, Cox and Cox (1976a) note that for parents who are older or who had been married longest, problems with changes in self-concept and identity were greatest in the immediate post-divorce period. On the other hand, Tessman (1978) and Wallerstein and Kelly (1974, 1976) note the advantages older children have in being able to emotionally and cognitively separate themselves from the parents' difficulties. They may be more able to understand the complexity of the situation and to maintain a significant relationship with the parent outside of the home.

Secondly, it is useful to gain some understanding of the role relationships and the patterns of handling affection, disagreement, separation, and so on, in the first marriage. While approaching the issues of separation from the point of view of individual therapy with the child, Tessman (1978) emphasizes the importance of family patterns of handling stress in determining the child's mode of dealing with separation and in influencing the length of time needed for resolution of the crisis. In fact, Tessman found similarities within families for different aged children were greater than were similarities across families with children of the same age. Hetherington, Cox, and Cox (1976b) note that the degree of role complementarity in the first marriage affects the amount of disruption experienced in the post-divorce period. In particular, fathers coming from first marriages in which there were rigid male-female role segregation in terms of household chores and child rearing experienced more disorganization immediately following the divorce than did men who had more equally shared household and child rearing tasks.

A third factor, important both in determining the child's ability to deal effectively with the transition from first marriage to separation and in determining the couple's ability to effectively separate from one another is the degree to which the child has been drawn into the original marital conflict. As Ackerman (1966) maintains, when a family has a disturbed child, there always is a marital disturbance. However, when there is a marital disturbance, the family does not always develop a disturbance in the children. The legacy of the defensive pattern which uses the child to defuse the marital conflict is that if the parents divorce, the child feels very guilty-all his sacrifices to save them have not been enough. He feels that it must be his fault, since all their arguments were about his behavior. This pattern is easily perpetuated in custody battles and inability of the parents to agree on anything in regard to the child. This continues a conflictual tie between them, but they are not able to resolve issues, because the arguments are over the wrong questions.

A couple which has been able to keep their conflict largely within the marital dyad, remaining mutually supportive in their roles as parents is more able to form arrangements in the best interests of the child. They may be able to carry out successfully a joint custody arrangement. These children will necessarily have feelings of responsibility for the divorce, and will distort events, but these reactions will be more of a temporary adjustment, a reaction to transition, than a continuing structuralized conflict.

Thus, if a child has an important role to play in the conflict between the parents, it 
becomes much more difficult for the child to come to terms with the separation and to work out continuing positive involvement with both parents simultaneously. The parents are much less able to offer the child help, support and clarification in the very difficult process. They themselves are unable to give up this important conflictual yet close tie in moving towards more distant, yet potentially more satisfying, separation. In this situation, there is little room for the stepparent to become as integrated in the new family. The child has no sense that he can have three or four effective parenting relationships. He feels that becoming close to his stepparent is the ultimate disloyalty to his noncustodial parent whom he is trying valiantly to support. Such a change would require him to abandon his role of keeping his parents connected. He may also offer himself in the second marriage for the same role. Drawing conflict onto himself, he helps the adults with any new difficulties that arise between them. Since there has not been an effective coparenting relationship established as a result of the first marriage, it is exceedingly difficult for the adults to establish that even more difficult co-stepparenting relationship in the second marriage.

In sum, these brief examples illustrate some of the ways in which the pre-separation family context is important in understanding the degree of disruption of the separation, the intensity of the loss experienced, and the patterns of coping with the loss for all family members. In addition, dysfunctional patterns from the first marriage which are not changed significantly become added baggage for the second marriage, interfering with the establishment of new family alliances.

\section{PERIOD OF PARTING}

Major tasks of the period of separation and divorce include dealing with the loss of intimate relationships, establishing an effective emotional divorce (Kressel \& Deutsch, 1977), establishing new relationships between each parent and child, and particularly for the adults, the development of a new level of self-respect and independence. Weiss (1975) emphasizes that any relationship in which a couple lives together for longer than two to four years has produced a significant and lasting attachment. Although the marriage may be legally dead, the attachment remains. This lasting bond is a highly ambivalent one. When progress toward emotional divorce is blocked the couple may continue to maintain a high level of negative feelings toward one another years after the legal divorce. The negative contact protects against the anxiety, confusion, sadness, and loneliness of losing the sense of predictable attachment. Paradoxically, it is less disruptive to pour energy into fighting an ex-spouse, a very familiar and comfortable stance, than it is to stand alone. For example, the role of "wronged woman" may be more comfortable and less risky than that of a "free and independent" woman.

The process of separation takes a long time. Weiss (1975) describes a course covering two to four years. Hetherington et al. (1976a) found that one year post-divorce was a time of high disruption for the families they studied, with a somewhat more stable equilibrium established by the end of the second year. There are an increasing number of excellent studies defining the course of the period of parting, examining differences in reactions for adults and children, and for children of different ages (Anthony, 1974; Hetherington et al., 1976a; Kelly \& Wallerstein, 1976; Wallerstein \& Kelly 1974, 1976; Weiss 1975). All emphasize the intensity of feeling involved for all family members. These studies underscore the importance of continued contact with and support from both parents for the children. Adults' reactions oscillate among feelings of exhilaration with their new freedom and independence, confusion over remorse and longing for the ex-spouse, bitterness at the necessity for being in this difficult position, and energetic, organized dealing with the tasks at hand. Hetherington et al. (1976a) found that as a group the children were more oppositional, aggressive, whining, complaining, dependent, and less 
able to sustain play. Tessman (1978) and Wallerstein and Kelly (1974, 1976; Kelly and Wallerstein, 1976) describe a range of grief reactions and modes of coping seen in children from preschool through adolescence. In addition, Tessman has observed that many children's reactions resurface periodically with new content and with defensive styles which are appropriate to new developmental levels. She adds that it is useful for the parent to clarify with the children his or her own progress and changing views of the ex-spouse so that both will understand more clearly that they are in the midst of an evolving process and that the intensity of the separation feelings will not last forever. As painful as it is, for both adults and children, moving through the mourning process is essential in order to form productive realignments within the family. Finally, the point of actual divorce always seems to be an important emotional event for all members of the family, even when coming after an effective and worked through separation.

In sum the immediate post-separation period is one in which all family members go through a mourning process in which they are dealing with a significant loss of an intimate relationship, and are beginning to work out a new, more distant relationship with the same person. The feelings, modes of dealing with these feelings, and goals of this period are different for both adults and children. The adults, in particular, are placed in the complicated and contradictory situation of needing emotional distance for an effective marital separation, while also needing to maintain enough positive feeling to continue a cooperative co-parenting relationship.

\section{THE ONE-PARENT FAMILY}

At the same time that they are going through the process of separation, the family is also establishing the structure of the one-parent family. The term "one-parent family" is somewhat misleading since it implies that there is only one parent in the picture. In fact, it is still a two-parent family with important physical and emotional separation between the two parents. Family members have the task of defining the family as extending beyond the boundaries of the living arrangement. They must organize in a very different manner than previously to fulfill all the necessary functions of daily living. Again, attention to the structure, problems, and patterns of effective coping for the one-parent family has increased tremendously during the past five years. What is critical from the perspective of the family which moves from this stage to that of a remarried family is that many of the structures and adjustments essential for effective functioning at the one-parent stage must be significantly rearranged in order for the effective integration into the remarried family. Particularly salient are the role of the parental child, the cohesion of the parent-child unit, and the shift for the adult from functioning in an interdependent spouse unit, to relying on her/himself as sole parent, to functioning as an interdependent unit with a stepparent.

An initial regressive solution is frequently a move back into the family of origin (Kaplan, 1977). Such a move may serve important temporary supportive functions, giving the parent a chance to deal with acute reactions, while insuring continued support and familiar surroundings for the children. It runs the risk, however, of recreating old conflicts between parent and grandparents over autonomy, competence, and the like. At times, the extended family, in order to protect their "own," will discourage and block the efforts of the divorced couple to talk to one another or to acknowledge mutual positive feelings. This can be an important disadvantage to the couple as they painfully negotiate the new ground rules between their households. The move into the grandparent's home can also become a more permanent dysfunctional solution if a structure evolves which keeps the parent from reassuming an independently functioning parental role.

Another common solution to the needs of the one-parent unit is the evolution of the role of "parental child." By necessity, the children assume a good deal of responsibility 
and independence. Often accompanying this change, the generational boundaries between parent and child become less distinct. There is a need for the children to take over some of the tasks previously carried out by the absent parent and to give a degree of emotional support. The child may be expected to carry certain responsibilities that he or she might not have had before, e.g., babysitting young siblings, helping to make decisions about the household, spending time alone without supervision, getting to school and back into the house again on his own. Frequently, these parental children show a good deal of responsibility and maturity. Tooley (1976) notes, however, there also may be discipline struggles. These struggles reflect a number of issues. The parent may be isolated from satisfying adult relationships and look to the child for closeness and support. The child reacts to these demands and may try to maintain a more comfortable distance by pushing away angrily. The child may protest what is perceived as a weak authority. The custodial parent also frequently receives a good deal of the child's anger about the new situation. The parent feels guilty, angry, ambivalent, unsupported and frequently has a good deal of difficulty sustaining firm, effective limits. With remarriage, this structure is expected to shift. If there have been disciplinary problems, frequently the stepparent is brought in as a strong authority support. However, if there has not been the development of a positive power base between the stepparent and the children, this authority is likely to fail.

The exclusive emotional dependence between the child and the parent may also shift dramatically with the parent becoming very bound up in the new adult loving relationship. The child then experiences a loss of this exclusive relationship and must share the parent without many obvious immediate rewards from the situation.

In addition, the parent who has felt guilty for the extra responsibility that the child has had to carry looks forward to the time when the child can be allowed to be a child again. There is no longer the need for the child to carry so many extra responsibilities or to spend time alone. The child, although probably happy to be relieved of the burdens or responsibility, does not easily move back to a less responsible, more dependent position. There may be a competition between the parental child and the stepparent over which one is a better parent to the younger siblings. If the previous responsibility and maturity is notacknowledged, the child may feel strongly displaced and highly resistant to the new family structure. The stepparent expects that moves he or she makes to help the child will be appreciated and experienced with relief. The stepparent is then quite taken aback when such gratitude is not forthcoming and, in fact, is resented. It is not infrequent that this child will run away from home or flee to the absent parent's household. Frequently, this child may feel that there is no place for him or her in either home. It would seem likely that an adaptive transition in these cases would be one which was gradual, had clear acknowledgement of the responsibilities and independence shown by the children in the one-parent family, had clearly defined tasks and transition, and maintained the responsible children's input into decision making.

The resistance to the forming of the remarried family unit comes not only from the children, however. The adults also have established painfully, and with a good deal of effort, newfound independence and responsibility in the one-parent stage. They have experienced the loneliness and vulnerability of the separation but also the exhilaration of being able to feel truly independent. There is a reluctance to give up this carefully built independence. An individual may not be sure how he or she can maintain differentiation while developing intimacy. It is common to hear one spouse or the other say, "We survived, we did quite well by ourselves before and we can do it again." If a single stepparent is joining the family, this person is confronted with a tight subgroup of the original one-parent family. It is very difficult for the stepparent to become part of this group, particularly if he or she does not have children. He or she may remain isolated, expected to control and discipline the children, to play certain roles, yet without the natural parent giving up the special closeness and giving the kind of support necessary for this 
transition to occur. When two families are merging, two subgroups with different histories are expected to form an integrated whole. Frequently, as disputes arise, the family will draw up battle lines which reflect clearly the original families.

\section{THE TIME OF COURTING WITH PLANS FOR REMARRIAGE}

The establishment of an intimate relationship with a new partner can be an important influence in the development of feelings of worth and self-confidence. Hetherington et al. (1976a) found this to be one of the most powerful supports for both the man and the woman in the post-divorce period. The move beyond intimacy, to the commitment to marriage signals the beginning of a new period of disruption and restructuring of family relationships.

Because of the significant structural shifts required in the transition between the one-parent family and the remarried family, the time of preparation for remarriage is critical in determining the balance of cooperation versus conflict in the early stage of the remarriage. Messinger (1976) describes seminars devised for couples planning remarriage, based on common issues emerging from her survey of a large group of remarried couples. Most couples contemplating marriage begin with a combination of hopeful idealism and pragmatic realism. They dream of a new start, hoping to avoid the mistakes they made in the past, and loving and supporting one another in a much more satisfying way. They feel they know themselves much better and are aware of the pitfalls of living intimately. They are well acquainted with the realities of parenting. However, they are highly sensitive, careful and protective. They do not wish more scars from the vulnerability of closeness. Despite all of their wisdom, however, no one who puts two families together has full awareness of the difficulty of this process. There are few models for effective stepfamilies and there are many myths which may be part of the unspoken marriage contract.

As illustrated in the following examples, families vary a great deal in the amount of preparation made for the remarriage. Mr. and Mrs. F. came to the clinic in the second month of their marriage. It was a third marriage for Mrs. F., but a majority of her time in the last few years was spent in a tight, one-parent unit with her son. Mr. F. was one year out of his first marriage of sixteen years. They had had a whirlwind courtship of three months with little time spent with his and her children together. Romantically, they had their remarriage on Valentine's Day, then moved in together. Mr. and Mrs. F. continued to hold down two full-time jobs, leaving her son and his daughter to cope with unsupervised time together. Needless to say, they were thrown totally off balance by the degree of conflict which erupted and had developed few ties between them strong enough to weather the storm. The marriage lasted barely six months.

The P. family also came to the clinic soon after their marriage, and carried with it a history of many years of difficulty. Mr. P.'s wife had deserted the family, to be replaced by a series of babysitters, some of whom had been abusive to the children. Mrs. P.'s children were adopted and felt acutely the loss of yet another parent. The blended family put together children of opposite sexes and similar ages who had already been attracted by one another. In contrast with the F. family, however, the P.'s spent a year preparing for the remarriage. They had many joint family outings and planning sessions for the move into the new house. The children knew one another and were beginning actively to share anecdotes of family histories. There were clear supportive alliances developing among the children, even before moving in together. Mr. and Mrs. P. were romantic, yet had made their marital contract fairly explicit. She gave up her employment, looking forward to spending time with the children. He changed his working hours to maximize time he and his wife could be alone while the children were in school, and to allow him to deal with his children when they arrived home. Their family also faced unexpected explosive situa- 
tions. However, they had done much more working through of early issues, and had been able to develop new family relationships which were resilient and flexible. When recontacted after three years, the family remained together and was actively worrying through some stressful adolescent years.

\section{EARLY REMARRIAGE}

The point of remarriage - the wedding event—usually sends ripples throughout the extended family system. For all the members of the "old family" it is a definitive indication that the fantasies of reunion must be given up. Even for well worked out divorces, it is likely to be upsetting for the ex-spouse, even if he or she is already remarried. The children may show a number of reactions. In one family, in which the parent and new stepparent had been living together, at the point of remarriage the children finally felt comfortable saying "Mom" and "Dad" instead of their first names. It was their recognition that this union was more permanent. Other children become more upset and fight suddenly the relinquishment of the hopes for reunion. The parents are often amazed at the difficulties which crop up between child and stepparent after the marriage, when they were so happy with the arrangement beforehand.

Clearly, the transition into remarriage will involve dealing with residual issues from the first marriage and the one-parent period as well as meeting the challenges involved in forming a functional remarried family system. The time of early remarriage is a period in which all the painfully established stability of the one-parent period is disrupted and in which family members are expected to live intimately with one another in role relationships which are ambiguous, contradictory, and ill-defined. Much of their prior experience based on two-parent first marriages leads to expectations which backfire when translated into step-relationships. "Socially approved" versions of complex families such as stepfamilies are becoming established very slowly. There is a protectiveness within the family which makes it more difficult to gather community support, and the complexity of the family system itself is overwhelming. Again, the process of reequilibration takes a long time. Roosevelt and Lofas (1976) comment that even in the strongest, most flexible and understanding stepfamilies they interviewed, it took three years before family members began to feel secure and satisfied. Visher and Visher (1978) believe that in the first three to four years the remarried family will either work out a viable solution or split apart. Having an understanding of the typical time span of such adjustments may be reassuring to families as they face the seemingly endless struggles of the first two years of remarriage.

Important tasks of the early remarriage are to establish a firm marital coalition, to develop stepparenting relationships which acknowledge the gradually strengthening bond of support and authority of the stepparent at the same time as clarifying and maintaining strong ties with the parent outside of the home, and to develop positive alliances among step- and half-siblings. The task is to define the nature of the boundaries around the stepfamily unit in a way which acknowledges the strong continuing ties with extended family members outside of the household while supporting the growth of new ties within the step-relationships. Several authors have delineated the special structural characteristics of the stepfamily which make this task particularly difficult (Roosevelt \& Lofas, 1976; Visher \& Visher, 1978; Walker et al., 1979; Walker \& Messinger, 1979; Whiteside, 1981). The boundaries around the stepfamily are at worst unclear and at best extremely permeable. Internal role structure is equally complex and ambiguous. Social network support is low, and extended family relationships may be strained. In addition, the creation of solutions to each of these tasks is complicated by the inevitable carryover of patterns of relationships from earlier stages. 


\section{ESTABLISHED REMARRIAGE}

There is virtually no literature describing experiences of families who have progressed past the very difficult first three years to the point of a clearly established working equilibrium of the remarried family. In these families, there is much more of a sense of stability and clarity about relationships than in the earlier stages of remarriage. However, each succeeding normal developmental change for family members must be dealt with not only in terms of its own requirements, but also in the context of the special relationships of the stepfamily. For example, as a child reaches adolescence he or she may need a period of time living with the absent parent because of increased feelings of confusion and discomfort in the remarried home, and/or because of the need to become well-acquainted with and to work out intensively the relationship with the absent parent. This may be a time in which the non-custodial parent has reached a stage of being able to become available with his/her children in a way not possible earlier. Addition of a child from a previous marriage then becomes an unsettling event for the new family. In clinical practice, it is common to see a remarried family whose carefully worked out stability has been seen as a new haven for "straightening out" a troubled child. All share in the hope of a new start. However, the child may bring with him a host of challenges which overpower the tenuous equilibrium of the complex remarriage. As discussed elsewhere (Whiteside, 1981), the remarried structure is one which operates from a chronic baseline of overload. Sometimes it does not take much extra stress to strain its resources. Again, the critical element in negotiating these crises seems to be a wellestablished and continually supported spouse subsystem in the remarriage. Couples who have described successful integration of adolescents from previous marriages have talked about being very clear with the adolescent about the role relationships and the ground rules of the family. They have been open with one another about their feelings and have presented their stance together. The stepparent has acknowledged and supported the special relationship of the biological parent and child, but also has been available as a communication route when needed. In addition, most remarried families with adolescents have evolved regular times for family meetings in which all members have important say in the running of the household. As the family becomes well established, patterns similar to those of the first marriages may appear. Some remarried couples evolve a structure in which the children are drawn into the marital disputes, forming dysfunctional triangles. Other couples are able to work together in co-parenting at the same time as having to deal with serious rifts in their own relationship.

In addition, even without the issue of changing custody or household arrangements, there always is the complexity for the adults of co-parenting with three or four parent figures as opposed to two. The children are continually reacting to and dealing with growing up in two households, three or four adult figures, and two or more models of relationship patterns with the opposite sex. It is likely that the child will deal differently with this complexity at different developmental stages. Some children block out one household, resisting visits for a time, while others try to keep them very separate. A child can attempt to make an integration by provocatively bringing disapproved of elements of one household into the other. Others negotiate the living situation like true diplomats, sensitively blending experiences with finely tuned awareness of each parent's limitations. Alternatively, a defensive solution can develop with the child using access to two homes as a means of avoiding dealing with issues in either family. Ideally, a child may gain from the opportunity of dealing with several caring adults. Based on growth and changes made in previous stages, the family's mode of mutual exchange may offer a newly productive mode of dealing with difference and disagreement, as well as more openness of feeling expression. There is the potential for a child to create for him or 
herself a unique combination of characteristics selected from all available sources. There is a continuing richness and potential flexibility in the wide range of experience and complex challenges presented in the stepfamily developmental process. Successful integration depends upon the negotiation of a series of tasks from all stages, and upon the continued evolution of the family structure in the face of new developmental challenges.

\section{REFERENCES}

Ackerman, N. W. Treating the troubled family. New York: Basic Books, 1966.

Albrecht, G. L. \& Gift, H. C. Adult socialization: Ambiguity and adult life crises. In N. Datan \& L. H. Ginsburg (Eds.), Life-span developmental psychology. New York: Academic Press, 1975.

Anthony, E. J. Children at risk from divorce: A review. In E. J. Anthony \& C. Koupernik (Eds.), The child and his family: Children at psychiatric risk. Vol. III. New York: Wiley \& Sons, 1974.

Barnhill, L. R. \& Longo, D. Fixation and regression in the family life cycle.Family Process, 1978, 17, $469-477$.

Hetherington, E. M., Cox, M. \& Cox, R. The aftermath of divorce. Paper presented at the meetings of the American Psychological Association, Washington, D.C., September, 1976. (a)

Hetherington, E. M., Cox, M. \& Cox, R. Divorced fathers. The Family Coordinator, 1976, 25, 417428. (b)

Kaplan, S. L. Structural family therapy for children of divorce: Case reports. Family Process, 1977, $16,75-83$.

Kelly, J. B. \& Wallerstein, J. S. The effects of parental divorce: Experiences of the child in early latency. A merican Journal of Orthopsychiatry, 1976, 46, 20-42.

Kressel, K. \& Deutsch, M. Divorce therapy: An in-depth survey of therapists' views. Family Process, $1977,16,413-444$.

Messinger, L. Remarriage between divorced people with children from previous marriages: A proposal for preparation for remarriage. Journal of Marriage and Family Counseling, 1976, 2, 193-200.

Ravenscroft, K. Normal family regression at adolescence.American Journal of Psychiatry, 1974,131, 31-35.

Roosevelt, R. \& Lofas, J. Living in step. New York: Stein and Day, 1976.

Solomon, M. A. A developmental, conceptual premise for family therapy. Family Process, 1973, 12, $179-188$.

Spiegel, J. The resolution of role conflict within the family. In W. C. Sze (Ed.), Human life cycle. New York: Jason Aronson, 1975.

Tessman, L. H. Children of Parting Parents. New York: Jason Aronson, 1978.

Tboley, K. The "man of the house" and his mother: Anti-social behavior and social alienation postdivorce. American Journal of Orthopsychiatry, 1976, 45, 33-42.

Visher, E. B. \& Visher, J. S. Common problems of stepparents and their spouses. American Journal of Orthopsychiatry, 1978, 48, 252-262.

Walker, K. N. \& Messinger, L. Remarriage after divorce: Dissolution and reconstruction of family boundaries. Family Process, 1979, 18, 185-192.

Walker, L., Brown, H., Crohn, H., Rodstein, E., Zeisel, E. \& Sager, C. J. An annotated bibliography of the remarried, the living together, and their children. Family Process, 1979, 18, 193-212.

Wallerstein, J. S. \& Kelly, J. B. The effects of parental divorce: Experiences of the preschool child. Journal of American Academy of Child Psychiatry, 1974, 14, 606-616.

Wallerstein, J. S. \& Kelly J. B. The effects of parental divorce: Experiences of the preschool child in later latency. American Journal of Orthopsychiatry, 1976, 46, 256-269.

Weiss, R. S. Marital separation. New York: Basic Books, 1975.

Whiteside, M. F. A family systems approach with families of remarriage. In L. E. Abt \& I. R. Stuart (Eds.), Children of separation and divorce: Management and treatment. New York: Van Nostrand and Reinhold, 1981. 